\title{
O controle remoto e a interatividade na televisão
}

\author{
Eduardo Natário 1 \\ Universidade Paulista \\ natariomail-2005@yahoo.com.br \\ Solange Wajnman² \\ Universidade Paulista \\ wajnman@aclnet.com.br
}

\begin{abstract}
Resumo: Esse trabalho realiza uma reflexão sobre a interface do Controle Remoto da televisão e a interação a partir da evolução das características tecnológicas desse meio. Procurando não nos fixar em uma abordagem hermenêutica, identificamos o Controle Remoto como uma variável importante para a composição da imagem da televisão. Ele contribui para tornar a programação da TV mais fragmentada, interativa e a imagem menos figurativa e mais gráfica. Percebendo o Controle Remoto de uma forma mais ampla, como algo extensor dos nossos sentidos, destacamos as interfaces que compõem a interatividade nas diferentes fases da TV, desde a primeira televisão eletrônica de 1927 até as evoluções tecnológicas do início desse século. Abordando o Controle Remoto tanto do ponto de vista conceitual quanto em relação à sua materialidade, ressaltamos o contexto da digitalização, da interatividade, do hibridismo tecnológico e da convergência das mídias.
\end{abstract}

Palavras Chave: Controle Remoto; Televisão; Interatividade

\footnotetext{
1 Jornalista com atuação em Internet, TV, jornal impresso, comunicação corporativa e elearning. Especialista em Teoria e Técnicas da Comunicação pela Faculdade de Comunicação Social Cásper Líbero e Mestre em Comunicação pela Universidade Paulista (UNIP).

2 Socióloga pela UFMG, Mestre em Psicologia Social pela PUC/SP e Doutora em Sociologia pela Université Renée Descartes, Paris V, Sorbonne. Professora do programa de pósgraduação em Comunicação da Universidade Paulista (UNIP). Co-autora de livros e autora de artigos na área de comunicação, tecnologia e moda.
} 


\begin{abstract}
This project analyzes the television set's Remote Control and interactivity interface based on the evolution of this medium's technological characteristics. Trying not to notice a hermeneutic approach, we identified the Remote Control as an important variable for the composition of television's image. The Remote Control contributes to rendering a television programming more fragmented, interactive, a less figurative image and more graph image. Noticing the remote control in a wider way, as something extending of our senses, we highlighted the interfaces that compose the interactivity during the different times of the TV, from first electronic television of 1927 to the technological evolutions of the beginning of that century. We covered the Remote Control both from the conceptual point of view and from its relationship with its materiality, researching the context of digitalization, interactivity, technological hybridism, and media convergence.
\end{abstract}

Keywords: Remote Control; Television; Interactivity

Résumé: $L$ ' article méne une reflexion sur l' interface de la Télécommande de la télévision et l'interaction a partir de l'évolution des caracteristiques technologiques de ce moyen. On n"est pas attaché dans un cadre herméneutique, on identifie la Télécommand en tant q'un élément important pour la composition de l'image de la télévision. Elle concourt pour rendre la programmation de la télévision plus fragmentée, interactive et l'image mons figurative et plus graphique.Envisageant la Télécommande dans un cadre plus général, en tant que extenseur de nos sens, on releve les interfaces qui composent l'interactivité dans différentes époques de la télévision, depuis la première télévision eletronique de 1927 jusq'aux évolutions technologiques du début du siécle. Envisageant la Télécommande aussi du point de vue conceptuel que par rapport à sa matérialité, on releve le context de la digitalization, de l'interactivité, de l'hibridisme technologique et de la convergence des mídias.

Mot-clé: Télécommande; Télévision; Interactivité

Resumen: Ese trabajo logra una reflexión sobre la interface del telemando de televisión y la interacción que empiezan de la evolución de las características tecnológicas de ese medio. Intentando usar un acercamiento no-hermeneutico, nosotros identificamos el telemando como una variable importante para la composición de la imagen de televisión. Él contribuye para volverse la programación de la televisión más fragmentada, interactiva y la imagen menos figurativa y más gráfica.Notando el telemando de una manera más ancha, como algo extenderse de nuestros sentidos, las interfaces que componen el interatividad en las fases diferentes de la televisión resaltaron, de primera televisión electrónica de 1927 a las evoluciones tecnológicas del principio de ese siglo. Acercándose el telemando del punto de vista conceptual y respecto a su materialidad, nosotros señalamos el contexto del digitalização, del interatividad, del hibridismo tecnológico y de la convergencia del mídias.

Palabras Claves: Telemando; Televisión, Interacción 


\section{Introdução}

No estudo da relação entre a interface do Controle Remoto com a televisão, sob o ponto de vista da interatividade, observamos uma evolução de características morfológicas e conceituais.

Partindo da premissa que o Controle Remoto modifica a composição da imagem da TV e que ele contribui para tornar a programação e a imagem desta fragmentada, propomos nos ater a visão que percebe a relação direta do avanço tecnológico com o aumento das possibilidades interativas.

Desde logo percebemos que a introdução do Controle Remoto e a presença ativa do espectador na TV, mudando de canal ou participando de um debate ao telefone, constituem variáveis importantes para a modificação da interface com a televisão.

Assim, a partir de um levantamento histórico da evolução tecnológica da televisão, abordamos o problema da digitalização e de sua associação com as questões relacionadas à interatividade. Para tanto é preciso seguir o caminho da interação através das diferentes fases da TV, que vão desde a primeira televisão eletrônica de 1927 até as evoluções tecnológicas do início do século XXI.

Recompondo a evolução da materialidade da televisão, dos padrões de Controle Remoto, das imagens televisivas (interfaces) e da história da televisão, podemos evidenciar as múltiplas modulações da interação na TV em diversas épocas e assim notar o hibridismo tecnológico e a convergência de mídias nesse meio de comunicação.

O pensamento sobre a comunicação do século passado reduziu a tecnologia a um ferramental e os Meios de Comunicação de Massa eram basicamente vistos de duas maneiras: A primeira visão é que tais tecnologias eram tidas apenas como veículos que surgiram e eram identificados como 'um visitante isolado' no espaço de vida das pessoas (a TV era vista apenas como um móvel a mais). A outra visão é que eram 'entidades' que superavam as pessoas enquanto veículos, representando um emissor-invasor (a TV era vista como uma 'entidade superior').

Sob o ponto de vista da tecnologia-máquina, hoje nos defrontamos com uma pluralidade comunicacional, na qual os meios não aparecem isolados nem as pessoas 
se expõem a eles isoladamente. Tal relação se estabelece numa prática conjugada: a relação do sujeito com a mídia é observada tanto na esfera da produção quanto na do consumo, estes últimos enquanto 'sistemas' acoplados.

Uma grande parte dos estudos e pesquisas que se multiplicaram a partir da década de 80 resultaram em trabalhos que envolvem a interação entre recepção e comunicação. Esses estudos se referem, em sua maioria, à relação entre os veículos de comunicação e o receptor. Até mesmo a denominação 'receptor' ainda evoca influências e pressupostos que orientaram os primeiros estudos sobre comunicação do início do século $\mathrm{XX}$ (onde o termo foi introduzido) e trazem uma relação de predomínio do emissor sobre o receptor. De fato, essa é a primeira relação que desponta e, na verdade, acreditamos não haver uma relação sempre direta, linear e absoluta do emissor em relação ao receptor, por isso entendemos que receptor não é sinônimo de passividade.

O pesquisador Mauro Wilton de Souza, no texto 'Recepção e comunicação: a busca do sujeito' observa que essa idéia de domínio total, no qual existe um emissor macro que verticalmente despeja informação sobre o receptor despojado e fraco, é uma idéia permeada de contradições, pois, não considera a existência de dois eixos de um processo mais amplo e complexo. Já as questões relativas à recepção "ainda estão vinculadas de forma mais próxima aos estudos de audiência, de opinião pública e de consumo, ou áreas de competência profissional, como publicidade, pesquisas de opinião e de audiência, marketing, etc.” (SOUZA, 1995, p.15).

Outros modelos teóricos surgiram e se propagaram por muito tempo, como o da fase hipodérmica e o da análise funcionalista da comunicação, privilegiando o ângulo psicossocial e tocando as relações de consumo. Percebemos que esses modelos sempre possuem relação com os paradigmas de sua época, tanto social como político e tecnológico.

A partir da década de 80 surgem as primeiras discussões sobre um caminho questionador da razão iluminista que se denominou pós-modernismo. Esse caminho é visto por alguns como algo que romperia com a história e com os modelos macroexplicativos até então vigentes, e por outros como um caminho histórico e 
importante, pois enfrentaria de forma realista e ousada as contradições a que o sistema sócio-econômico chegou na atualidade.

O fato é que a visão pós-moderna e, sobretudo aquela que nos propomos aqui (abordagem da materialidade) se posiciona no início do século XXI com algumas diretrizes diferentes. São vários os aportes que contribuem para esta abordagem: Walter Benjamin, Mc Luhan, Jacques Derrida, Pierre Levy e Hans Ulricht Gumbrecht.

Enquanto no modelo frankfurtiano se buscava o 'quem' do processo, este enfoque contemporâneo contempla a visão pós-moderna e trata do 'como' no processo da comunicação.

Assim a abordagem da presente pesquisa, que trata da materialidade dos meios de comunicação, traz um enfoque metodológico muito importante mais pouco estudado. Essa abordagem privilegia as formas, as características dos meios, a tecnologia e as relações cognitivas envolvidas nos processos sem julgar ou interpretar o conteúdo dos meios de comunicação, ou seja, adotando uma abordagem não hermenêutica. Erick Felinto e Vinicius Andrade expressam bem essa abordagem:

Trata-se, por fim, de se considerar a plausibilidade, dentro de um projeto epistemológico que recupere e se ocupe das questões materiais que envolvem as práticas sociais e as suas formas de comunicação - da fala, às tecnologias digitais - considerando a cultura a partir dos corpos, das presenças e das vidas dos objetos (FELINTO e ANDRADE, 2004, p 91).

\section{Interação, interatividade e suporte material}

Para propor a idéia do Controle Remoto como configurador da interatividade na televisão, sob o ponto de vista da materialidade, devemos em primeiro lugar mostrar conexões entre configurações tecnológicas diferentes e suas bases materiais.

Partimos do fato de que a palavra falada é a primeira tecnologia pela qual o homem pôde desvincular-se de seu ambiente para retomá-lo de novo modo. E é a partir dessa observação que podemos traçar uma breve evolução das tecnologias usadas como meios de comunicação e suas implicações. 
Depois da anotação mnemônica quipu dos Incas, usada para registrar cálculos, eventos e datas importantes, da invenção da escrita cuneiforme pelos sumérios por volta de 3400 a.C., do alfabeto fenício em 1000a.C., inúmeras outras tecnologias de enunciação e comunicação surgiram até o advento da televisão.

Vale ressaltar que todos os exemplos citados possuem suas particularidades e uma característica em comum importante: possuem algo que possibilitou o transporte dessa comunicação. Seja o ar que transporta a voz, os cordéis que dão suporte à mnemônica quipu, ou as placas de barro que suportam a escrita cuneiforme, todos estão intrinsecamente ligados a sua materialidade.

Nos reportando ao Controle Remoto em si e ao seu contexto, destacamos o 'botão' como uma das criações que sempre trouxe consigo a idéia de 'alcançar algo distante', portanto prolongando os sentidos de quem o usa. Desde suas primeiras aplicações como sinetas de portal, cuja função era chamar os criados nas casas burguesas, até as campainhas das casas ou ainda nos aparelhos de telegrafo, tal objeto que hoje está presente em todos os controles remotos das TVs, sempre serviu para 'disparar uma ordem à distância' ou 'mudar uma situação'.

Os novos meios e tecnologias pelas quais prolongamos nossos sentidos constituem várias incisões (mudanças) no coletivo: Televisão, Controle Remoto, videogame, cinema, telefone, Internet são alguns desses meios tecnológicos mais conhecidos atualmente.

As tecnologias ajudam a compor a história da cultura humana e causam impacto nos sentidos se impondo e contaminando o sistema nervoso dos participantes.

No início da televisão, a baixa definição, composta por poucos pontos na tela, aguçava em muito a imaginação dos espectadores. Apesar do padrão de 405 linhas de resolução da TV inglesa ser apontado como 'alta resolução', as imagens eram deficientes e a todo o momento os espectadores tinham que decodificar tons, sobras e 'fechar' formas abusando do efeito de Gestalt' ${ }^{1}$.

\footnotetext{
${ }^{1}$ Gestalt: Teoria relativa a fenômenos psicológicos e biológicos que considera as imagens em conjuntos, como unidades autônomas. A Gestalt prevê a configuração do 'todo' e considera o fator de 'fechamento visual' importante para a formação de unidades. (Gomes, 2000).
} 
Nesse início a interação mais comum ao meio televisivo era proporcionada pelo efeito de Gestalt, que exigia do espectador um esforço para 'arredondar os conjuntos' e extrair sentido dos sinais televisivos. Já na época da 'TV Interativa Digital de Alta Definição' a interatividade aponta para outros tipos, como a imersão em menus e personalização de opções.

Diferentemente da imagem do cinema e da fotografia, a imagem da TV sempre precisou de muito envolvimento (interação) do espectador no momento da recomposição das formas (Gestalt não-verbal) por apresentar baixo teor de informação visual.

Desde aquele modo de interação mais primitivo, que se estabelece quando decodificamos imagens de baixa resolução, até aquele mais recurso sofisticado² no qual compartilhamos informação multimídia diretamente com outras pessoas através da TV, notamos que desde sempre a TV é envolvente e estabelece interação em várias escalas.

Sobre o problema da interatividade e a existência do participante, Pierre Levy em seu livro Cibercultura observa que o termo Interatividade, em geral, ressalta uma participação ativa do beneficiário de uma transação de informação e completa dizendo que:

de fato, seria trivial mostrar que um receptor de informação, a menos que esteja morto, nunca é totalmente passivo. Mesmo sentado diante de uma televisão sem controle remoto o destinatário decodifica interpreta, participa, mobiliza seu sistema nervoso de várias maneiras e sempre de forma diferente de seu vizinho (LEVY, 2000, p. 79).

Como Pierre Levy ressalta ‘a não ser que ele esteja morto’ o espectador está sempre interagindo, pois o simples fato de ser atingido pelos raios catódicos da TV já configura interação com o meio. Também notamos que na recepção não há controle sobre como e em que contexto tal conteúdo é recebido. Isso nos ajuda a perceber que há muitas reações diferentes na recepção do audiovisual e que os espectadores sempre são parte ativa possuindo, inclusive, suas particularidades.

\footnotetext{
${ }^{2} \mathrm{O}$ recurso que permite compartilhar informação multimídia e vídeo com outras pessoas está presente nos set-top boxes TiVo, disponível nos Estados Unidos. Para promover esse recurso essa caixa decodificadora é acoplada a TV e a meios que permitem o tráfego bidirecional de dados em alta velocidade.
} 


\section{O percurso histórico do controle remoto}

Usaremos a palavra Controle Remoto dentro de um conceito abrangente. Quando nos referimos a esse controle à distância não estamos apenas fazendo referência ao aparelho de Controle Remoto em si, mas também ao conceito de alcançar algo à distância que está implícito em várias ações ligadas à interação na televisão, como vimos acima.

Mesmo antes de o Controle Remoto chegar ao Brasil, nos Estados Unidos já existia uma vontade de tornar a televisão mais envolvente, e nessa aspiração também já estava contido o conceito do Controle Remoto.

Nos anos 50 a televisão norte-americana ensaiava programas interativos dentro de desenhos animados, como é o caso da série chamada 'Winky Dink and You', que já propunha um modelo simples de participação. Nessa primeira empreitada a personagem saía em uma aventura e, em determinado momento, necessitava da 'ajuda' da audiência. Para interagir com o programa as crianças precisavam ter em mãos o 'Winky Dink Kit', formado por uma folha de plástico transparente, uma flanela e alguns lápis de cera. No momento em que a personagem se encontrava em apuros ela se dirigia à audiência e solicitava ajuda do público, pedindo para as crianças colocarem a folha de plástico na frente da televisão e, por exemplo, desenhar uma ponte para Winky atravessar um rio.

No desenho Winky Dink, depois do estímulo da personagem do desenho animado, o espectador dispara uma ação à distância colocando a folha de plástico sobre a tela da TV ‘ajudando' a personagem e completando a interação no desenho.

Algo semelhante ocorre quando mudamos de canal na televisão com um aparelho de Controle Remoto em mãos; disparamos uma ação à distância e o aparelho de TV 'responde' com uma imagem nova. Também enxergamos esse conceito de Controle Remoto em várias outras ações interativas relacionadas à TV.

As características dos meios (hardware) e a cognição estão intimamente ligadas. Muitas vezes o acréscimo de mais uma variável no ambiente, como o aparecimento do Controle Remoto na televisão, faz muita diferença na maneira de pensar das pessoas envolvidas. 
Quando a TV passou a explorar mais essas oportunidades interativas, os programas foram tomando outras formas e aos poucos readaptando sua interface para os novos contextos.

Nos anos 60 o apresentador Silvio Santos apresentou um quadro chamado 'Justiça dos Homens', onde a platéia e os jurados participavam decidindo o resultado de um caso apresentado.

Outros exemplos na mesma linha de 'Justiça dos Homens' se sucederam pela TV. No policial 'Linha Direta' da Rede Globo, inspirado no inglês 'Crimewatch UK' (1984) e no programa alemão chamado 'File XY Unsolved', as pessoas ligavam passando pistas sobre os casos reais, reconstituídos por atores, e a produção investigava as novas informações para depois mostrar a resolução.

O programa 'Você Decide', também da Rede Globo, exibia uma história fictícia e pedia para o público escolher entre dos dois finais propostos. O público participava ligando gratuitamente para um telefone com prefixo 0800 e dos dois finais pré-gravados, apenas o desfecho escolhido pela votação popular era exibido.

Também usando o telefone para permitir a interação dos espectadores, em 1984 o Sistema Brasileiro de Televisão, SBT, estreava o videogame 'TV Pow'. Nesse programa, crianças e adolescentes podiam participar gritando "Pow!” no bocal do telefone para disparar um comando à distância.

Hugo Game é outro exemplo da busca pela interatividade na televisão através do telefone. Hugo é um programa de televisão interativo, produzido pela produtora dinamarquesa Interactive Television Entertainment, que fez da TV um videogame. Esse jogo é um programa de televisão no qual um espectador controla a personagem virtual na tela da TV da mesma maneira que em um videogame convencional. A diferença é que a personagem é controlada à distância pelo teclado do telefone, e não por um joystick convencional ou mouse.

Anos depois a MTV Brasil lançou um game show nos mesmos moldes do Hugo Game. Intitulado 'Garganta e Torcicolo’ o game televisivo possuía o mesmo mecanismo e formato, mas com personagens diferentes.

Tanto no Hugo Game quanto no programa da MTV a personagem virtual é controlada pelo teclado do telefone. Deve-se teclar no aparelho algumas teclas 
específicas para que o movimento ocorra. As teclas são: '4' movimenta o personagem para a esquerda, ' 2 ' para cima, ' 6 ' direita e ' 8 ' para baixo. Essa combinação de teclas forma um joystick imaginário no teclado do telefone, e a partir dele a partida é intermediada.

O telejogo Hugo é mais conhecido pelo programa televisivo, mas também está presente em outras plataformas e amplia a convergência de mídias. Além dessa versão de game para $T V$ Broadcast, existem outras feitas para Internet, Telefones Celular, Playstation, GameBoy, PC e DVD.

A convergência de mídias na televisão tem um reforço com o lançamento da WebTV Network, em 1996 nos Estados Unidos e em 1999 no Brasil. Dessa vez o computador se une à TV permitindo ao espectador assistir televisão e acessar a Internet ao mesmo tempo, declarando o início dos itens híbridos que conjugam TV e Computador.

A WebTV permite acessar conteúdos da Internet na TV e foi testada em novembro de 1999 durante o evento 'Expo Comm 99', em São Paulo. Durante a exibição de uma entrevista as informações anexas com dados do da exposição, do entrevistado e da empresa para qual ele trabalhava podiam ser acessadas usando um Controle Remoto, bastando o espectador clicar sobre o entrevistado para obter informações.

Vale lembrar que a WebTV é uma empresa da Microsoft e usa uma tecnologia intermediária, que não é 100\% digital, combinando a imagem analógica do programa de televisão com as informações digitais retiradas da Internet. Notamos que essa experiência faz convergir TV e Internet em um sistema híbrido e só foi possível através da parceria entre quatro empresas: a operadora de TV a cabo TVA, o Sistema Brasileiro de Televisão - SBT, o provedor de Internet Ajato e a empresa de Conteúdo Digital MediaCast.

Até o ano de 2004 essa iniciativa com a WebTV no Brasil ficou só na experiência, mas em Portugal o sistema foi lançado comercialmente no mercado em 2001 pela TV Cabo Interactiva. Além da TV portuguesa, as redes alemãs ViaSAT (satélite) e TeleDenmark (cabo) também utilizam essa tecnologia de interação: A 
primeira juntando satélite e Internet banda larga, e a segunda cabo e Internet banda larga.

Um dos programas de mais sucesso das transmissões interativas alemãs é o 'ROEFL', um programa ao vivo de estúdio direcionado para jovens, que é exibido pelas duas operadoras de TV por assinatura citadas, e mesmo possuindo tecnologias diferentes unem esforços para dispor a mesma interação em ambas plataformas.

Além dessas visíveis alterações da interface gráfica da televisão, promovidas por jogos e demais ações que pedem o engajamento do espectador, outro tipo de alteração da imagem da televisão aconteceu por causa das novas possibilidades tecnológicas. A mais comum delas é o recurso de 'múltiplas janelas', muito usado nos telejornais, que fez muitos programas dividirem suas telas em duas ou mais imagens diferentes para fazer link entre lugares distantes; outro recurso é o das 'tarjas gráficas' com títulos que acompanham as imagens ou complementam as informações.

O exemplo decisivo da tecnologia que incidiu e causou modificações no âmbito social foi a inserção do Controle Remoto ao aparelho televisor. A acoplagem desse meio de comunicação à mão humana transformou e está transformando as maneiras de assistir televisão e de pensar diante da tela. No entanto, como vimos, este não é um fenômeno novo do ponto de vista conceitual.

O surfe televisivo, como também é conhecido o zapping entre os canais, já foi muito diferente do que conhecemos hoje. A chegada do botão elétrico e dos painéis de controle com vários botões facilitaram o acesso aos canais da TV. A partir dessa pequena revolução se podia ir direto ao número do canal que desejasse, sem ter que girar um disco e obrigatoriamente passar por outros canais.

Primeiro foram os seletores de girar, em seguida acompanhamos experimentos de controles com fio, depois sem o fio, até os modelos atuais quebrarem definitivamente o paradigma da TV sem Controle Remoto.

Atualmente é comum um Controle Remoto trazer consigo traços da convergência de mídias e de hibridismo tecnológico, que acompanhamos com mais intensidade nesse início de século. Alguns Controles já são múltiplos e além de servirem para mudar o canal da TV ainda controlam set-top boxes (caixas decodificadoras), vídeo cassetes, aparelhos de DVD e outros equipamentos. 
Já na interface imagética são comuns menus interativos, como no caso das operadoras de TV por assinatura DirecTV e $S k y$, que trazem legendas em várias línguas e informações extras ancoradas por menus digitais de textos e figuras.

A interatividade concedida nos casos brasileiros de televisão por satélite une os seguintes dispositivos: TV, set-top boxes, Controle Remoto multifuncional (que controla televisão e satélite) e telefone fixo para permitir o $T$-Commerce e a compra de eventos em pay-per-view.

Diante desse panorama identificamos que atualmente o Controle Remoto se torna o Totem dessa situação interativa, pois é principalmente através dele que a interatividade nos é proporcionada.

\section{Considerações finais}

A principal reflexão que trazemos é a idéia de que o Controle Remoto pode ser identificado como um Totem, um verdadeiro símbolo da contemporaneidade pósmoderna, que se encontra inundada de imagens desreferencializadas ${ }^{3}$.

Junto ao Controle Remoto e nessa situação pós-moderna percebemos que as idéias de interatividade, hibridismo e convergência guiaram as comunicações nas últimas décadas, pois sempre estiveram presentes nesse contexto.

A interface imagética da televisão mudou sua característica e com o tempo essa imagem passou de predominantemente figurativa para uma 'imagem gráfica', resultando em conteúdos visuais desnaturalizados.

Essa predominância gráfica se acelerou a partir da digitalização dos meios de comunicação e se firmou com o surgimento do Controle Remoto, pois ele ajudou no processo de fragmentação da a imagem da televisão e na 'perda do significado figurativo das imagens'.

A partir do estudo da interface do Controle Remoto e das tecnologias que envolvem a TV, percebemos que a televisão sempre proporcionou interação e o aparelho de Controle Remoto contribuiu para reforçar essa característica permitindo uma maior participação do espectador em vários níveis.

3 Imagens desreferencializadas ou 'desnaturalizadas' são imagens que não trazem uma referência segura de um mundo externo ou do mundo natural como conhecemos. 
Nossos estudos revelaram uma TV intrinsecamente ligada à interação, ou seja: desde sempre ela foi envolvente e ainda é, até os dias de hoje, de diferentes maneiras e intensidades.

No início a interação estava concentrada no olhar do espectador (relativa à cognição, interpretação) quando 'decodificava' as imagens de baixa resolução e pouco nítidas através do recurso da Gestalt visual.

Em seguida surgiram o videoteipe, a TV em cores e outros recursos tecnológicos que consolidaram as características desse meio, como a fragmentação da programação, o hibridismo, a convergência dos meios e outros relativos à produção; mas foi a introdução do Controle Remoto que deixou clara a idéia de interatividade na televisão.

Os novos meios e tecnologias pelas quais 'prolongamos os sentidos' promovem várias mudanças no âmbito social. O surgimento do Controle Remoto no aparelho televisor foi um fator que causou modificações no cotidiano social dos espectadores.

Assim, as novas variáveis do contexto televisual são importantes, devem ser levadas em conta, e foi sob essa ótica que esse estudo se desenvolveu. Abordamos a evolução das tecnologias e a interação que elas concedem nas diversas épocas, seja nos primórdios da invenção da TV ou no paradigma da TV Interativa de Alta Definição.

O caminho da convergência de mídias ratifica o aperfeiçoamento da TV e consolida a união dela com o computador. Esse movimento aponta para uma situação na qual os espectadores têm um papel mais participativo do que aquele que desempenharam antes das convergências e do surgimento do Controle. Agora o espectador com o Controle, e o poder que ele oferece, vai além do envolvimento natural que o meio televisivo já estabelece; o espectador de fato participa do jogo interativo.

Nesse paradigma o espectador muda de figura e não deve ser visto apenas como editor e zapeador da programação da televisão, mas de fato como participante e criador de sua própria programação. 
Como já exposto, a interação mais comum nos primórdios da televisão era aquela que se dava pelo efeito de Gestalt. Já na época da 'TV Interativa Digital de Alta Definição' a interatividade aponta para outros tipos como a imersão em menus (concedida pelo hibridismo tecnológico) e personalização de opções.

O caminho da digitalização e da personalização da televisão permite que haja uma descentralização da comunicação que transforma profundamente o modo de ver TV. Essa mudança é promovida pelo Controle Remoto que ganha novas funções e agora permite navegar por menus digitais, entre imagens de diferentes dispositivos como DVD, satélite, bibliotecas pessoais multimídia e caminha para o compartilhamento de conteúdos em rede através da TV. Tal avanço de interatividade e poder concedido por esse Controle Remoto o elevam a Totem de nosso tempo.

A criação de programação individualizada na TV acontece quando o meio possibilita uma gama de combinações diferentes possíveis e oferece uma forma fácil de recombinar esses conteúdos.

O intercâmbio de vídeos através do ciberespaço da tevê diretamente entre as pessoas acontece a partir da fusão da tecnologia digital bidirecional com a televisão. O tipo de interatividade potencial concedida pela Internet reforça nossa hipótese de que o Controle Remoto é uma interface importante na configuração da interatividade na televisão, pois é a partir dele que a interatividade dos níveis mais avançados é possível.

Essa potencialidade quando transportada para a televisão tende a construir laços (comunidades) da mesma forma que acontece com as possibilidades da Internet como e-mail, newsgroup e grande segmentação.

Para citar mais um indicador dessa tendência natural de convergência, além das já mencionadas anteriormente, a migração do serviço de comunicação individual (um - um) para televisão leva o serviço de troca de mensagens interpessoais à TV e reforça a tendência de destotalização da nova televisão digital interativa.

A desreferecialização é observada no comportamento social, na tecnologia e na imagem da TV; ou seja, em todos esses campos surgem situações que não possuem relação direta e clara com experiências anteriores, estabelecendo novos paradigmas 
em curto espaço de tempo (como o surgimento do mp3, telefone celular, imagens virtuais).

Da mesma forma que pensar diante de uma máquina de escrever é diferente de pensar diante de um processador de texto de um computador, tanto pelas particularidades da materialidade quanto pelo cenário cognitivo, a inserção do Controle Remoto também transformou a forma das pessoas verem TV quando empunham o controle e podem ter escolhas à mão.

O Controle Remoto permite acelerar a fragmentação da imagem da tevê. Tal relação se aplica à conformação da imagem que agora se encontra mais desreferencializada do que nunca e está em consonância com a situação pósmoderna, na qual os meios de comunicação hoje se encontram.

Em um zapping uma 'cena nova' não possui relação com a anterior e a construção que cada um faz é única. Isso faz com que não seja raro um espectador apenas ‘contemplar a imagem' sem se importar com o que tais cenas signifiquem. Por vezes não se encontram mais nessas cenas, ou nessa frenética alternância de imagens, referencias ou equivalentes no mundo real.

A ação do Controle Remoto na tevê, nesse cenário pós-moderno e de imagens desreferencializadas, faz desse objeto um representante ilustre (Totem) dessa visão de do mundo contemporâneo, pois é ele que permite a catalisação de tal situação imagética.

A digitalização dos vídeos domésticos e o compartilhamento destes com outras pessoas, como uma comunidade virtual em rede, contribui para reafirmar mais um conceito pós-moderno, o da destotalização.

Mesmo com as tendências descritas acima, é difícil criar modelos imperativos e universais em uma sociedade com esse panorama, pois a própria falta de referência não permite criar leis estanques, mas sim identificar tendências, mostrar caminhos e reconhecer as características dos meios de comunicação. 


\section{Referências:}

ARNHEIM, R. Arte e percepção visual: uma psicologia da visão criadora. São Paulo: Pioneira/ Edusp, 1997, p. 33-86.

BENJAMIN, Walter. A obra de arte na época de suas técnicas de reprodução. in Os Pensadores, São Paulo: Abril S.A. Cultural, 1983, pp 4-28

BERNARDO, Nuno. O Guia Prático da Produção de Televisão Interactiva. Lisboa Portugal: Editora Centro Atlântico, 2002.

COELHO, T. Modos culturais pós-modernos. Moderno Pós Moderno: modos \& versões. São Paulo: Iluminuras, 1995, p. 172-227.

CONNOR, Steven. Tv, vídeo e filme pós modernos. Cultura Pós-Moderna Introdução às teorias do contemporâneo. São Paulo: Edições Loyola, 1992, p.129-149. e p.82-85.

DARIN, Leila de Mello. A relação texto-leitor na teoria da recepção. São Paulo, 1990, 241-251.

FELINTO, Erick. Materialidades da comunicação: por um novo lugar da matéria na teoria da comunicação. IN CIBERLEGENDA. Rio de Janeiro, RJ, n.5, 2001. Programa de Pós-graduação em Comunicação, Imagem e Informação da Universidade Federal Fluminense. Disponível em: http://www.uff.br/mestcii/felinto1.htm< Acesso em 28 nov.2005 ; ANDRADE, Vinícius. A Vida dos objetos: um diálogo com o pensamento da materialidade da comunicação. Revista Contemporânea. Salvador: Programa de Pós-graduação em Comunicação e Cultura Contemporâneas da Universidade Federal da Bahia, volume 3, n.1, p.75-94, janeiro/junho 2005.

FERDINÁN, V. Materialidade da arte: estética da preponderância do objeto. Interseções: a materialidade da comunicação. Rio de Janeiro; Imago/ EDUERJ, 1998, p.85-97.

GOMES, João Filho. Leis da Gestalt: Sistema de Leitura Visual da Forma. São Paulo: Escrituras, 2000.

GUMBRECHT, Hans Ulrich. Corpo e forma; ensaios para uma critica não hermenêutica. Rio de Janeiro: Ed UERJ, 1998, capítulo V.

Cascatas da modernização in Interseções: a materialidade da comunicação. VI Colóquio UERJ, Rio de Janeiro: Ed. Uerj e Imago, s.d, 1998, pp 23-39.

. As conseqüências da estética da recepção: um início postergado. In: Corpo e forma. Rio de Janeiro: ed. UERJ, 1998.

HARVEY, David. Condição pós-moderna: uma pesquisa sobre as origens da mudança cultural. 8. ed. São Paulo: Loyola, 1999. 
JACOMY, Bruno. A era do controle remoto - Crônicas da inovação técnica. Jorge Zahaar Editor, 2004

JAMESON, Fredric. Espaço e imagem. Rio de Janeiro: Ed.UFRJ, 1994.

Pós-Modernismo: A lógica cultural do capitalismo tardio. Série temas - volume 41 - Cultura e Sociedade, Ed. Ática, 1996.

JOHNSON, Steven. Cultura da Interface, como o computador transforma nossa maneira, de criar e comunicar. Rio de Janeiro: Jorge Zahaar Editor, 2001

LEVY, Pierre. Cibercultura. Trad. Carlos Irineu da Costa. São Paulo: Editora 34, 2000.

As Tecnologias da Inteligência. Trad. Carlos Irineu da Costa. São Paulo: Editora 34, 1998.

. O que é virtual. Trad. Paulo Neves. São Paulo: Editora 34, 1997.

MACHADO, Arlindo. A arte do vídeo. São Paulo: Ed. Brasiliense, 1990

. Máquina e imaginário. São Paulo: EdUSP, 1993.

MAFFESOLI, Michel. Elogio da razão sensível. Petrópolis, Vozes, 1998.

. O conhecimento comum, Compendio de sociologia compreensiva. São Paulo: Ed. Brasiliense, 1998.

MCLUHAN, Marshall. Os meios de comunicação como extensões do homem. São Paulo: Ed. Cultrix, 1964.

NATARIO, Eduardo S. O Controle Remoto como configurador da interatividade na televisão. Dissertação (Mestrado em Comunicação) - Universidade Paulista, 2005.

QUÉAU, PHILIPPE. O Tempo do Virtual. in PARENTE, André (org) Imagemmáquina.

SOUZA, Mauro Wilton de. Recepção e comunicação: a busca do sujeito in O lado oculto do receptor. São Paulo: Ed. Brasiliense, 1995.

WAJNMAN, Solange. Pós-Modernidade e Análise Formista. in Revista Textos, Universidade Federal da Bahia, número 3 7/3 8,1997 